\title{
Consumo de alimentos e hábitos de vida de uma amostra de idosos de Campo Grande, MS
}

\section{Food intake and life habits of an elderly sample from Campo Grande, MS}

Consumo de alimentos y hábitos de vida de una muestra de personas mayores de Campo Grande, MS

\author{
Letícia Egídio Arelhano ${ }^{1}$ \\ Fernanda Zanoni Cônsolo ${ }^{2}$ \\ Teresa Cristina Abranches Rosa ${ }^{3}$ \\ Giovana Eliza Pegolo ${ }^{4}$
}

${ }^{1}$ Graduada em Nutrição pela Universidade Federal de Mato Grosso do Sul (UFMS). E-mail: leticia_arelhano@hotmail.com, Orcid http://orcid.org/0000-0002-1367-0594

${ }^{2}$ Docente do Curso de Nutrição e do Programa de Residência Multiprofissional em Atenção ao Paciente Crítico, da Universidade Federal de Mato Grosso do Sul (UFMS) E-mail: fernandazanoni@yahoo.com.br, Orcid: http://orcid.org/0000-0002-0812-2817

${ }^{3}$ Doutoranda do Programa de Pós-Graduação em Saúde e Desenvolvimento na Região Centro-Oeste da Universidade Federal de Mato Grosso do Sul (UFMS). Nutricionista (UFMS). E-mail: teresa.rosa@ufms.br, Orcid: http://orcid.org/0000-0002-9990-6560

${ }^{4}$ Doutora em Alimentos e Nutrição pela Universidade Estadual Paulista (UNESP). Mestre em Ciências pela Universidade de São Paulo (USP). Docente do Curso de Nutrição e do Programa de Residência Multiprofissional em Atenção ao Paciente Crítico, da Universidade Federal de Mato Grosso do Sul (UFMS). E-mail: giovana.pegolo@ufms.br, Orcid: http://orcid.org/0000-0003-2636-2547 
Resumo: Objetivou-se descrever a frequência de consumo de alimentos classificados como saudáveis, processados e ultraprocessados e fatores associados entre idosos. Trata-se de estudo transversal, constituído por amostra de conveniência, proveniente de um Centro de Convivência de Idosos de Campo Grande (Mato Grosso do Sul). Foram investigadas variáveis referentes à frequência de consumo de alimentos e hábitos relacionados à saúde (atividade física, álcool, tabagismo, diagnóstico de doenças). As mulheres apresentaram frequências de consumo semanal menor, para alimentos processados/ultraprocessados, e maior, para alimentos in natura, quando comparadas com os homens. A frequência semanal de atividade física $\geq$ a 3 dias associou-se $(p<0,0001)$ ao sexo feminino $(94,4 \%)$. Considerando ambos os sexos, $61,8 \%$ declararam diagnóstico de hipertensão, e 22,4\%, de diabetes. A frequência de 3 ou mais doenças foi maior entre as idosas $(p<0,05)$. Os resultados apontam que as mulheres apresentam maior frequência de consumo de alimentos saudáveis e de atividade física.

Palavras-chave: atividade física; envelhecimento; hábitos alimentares.

Abstract: The aim of this study was to describe the intake frequency of foods classified as healthy, processed and ultra-processed, and associated factors among the elderly. This is a cross-sectional study, consisting of convenience sampling, from a Daycare Center for the Elderly in Campo Grande (Mato Grosso do Sul). We investigated variables related to sample characterization, food intake frequency and health habits (physical activity, alcohol intake, smoking, illnesses diagnosis). Women present lower weekly intake frequencies for processed/ultra-processed foods and higher values for in natura foods, when compared to men. The weekly frequency of physical activity $\geq 3$ day was associated $(p<0.0001)$ to females (94.4\%). Considering both sexes, $61.8 \%$ declared a diagnosis of hypertension and $22.4 \%$ of diabetes. The frequency of 3 or more diseases was higher for female elderly $(p<0.05)$. The results show that women present higher frequency of healthy foods intake and physical activity.

Keywords: physical activity; aging; eating habits.

Resumen: El objetivo de ese estudio fué describir la frecuencia de consumo de alimentos clasificados como saludables, procesados y ultraprocesados, y factores asociados entre personas mayores. Es un estudio transversal, constituido por una muestra de conveniencia, proveniente de un Centro de Convivencia para Personas Mayores de Campo Grande (Mato Grosso do Sul). Fueron investigadas variables referentes a la caracterización de la muestra, frecuencia de consumo de alimentos y hábitos relacionados a la salud (actividad física, consumo de alcohol, tabaquismo, diagnóstico de enfermedades). Las mujeres presentan frecuencias de consumo semanal más bajo para alimentos procesados/ultra procesados y mayores para alimentos in natura, cuando comparados con los hombres. En la frecuencia semanal de actividad física $\geq 3$ días asociado $(p<0,0001)$ al sexo femenino $(94,4 \%)$. Considerando ambos los sexos, 61,8\% declararon diagnóstico de hipertensión y $22,4 \%$ de diabetes. La frecuencia de 3 o más enfermedades fue mayor entre las personas mayores $(p<0,05)$. Los resultados apuntan que las mujeres presentan mayor frecuencia de consumo de alimentos saludables y de actividad física.

Palabras clave: actividad física; envejecimiento; hábitos alimentarios. 


\section{INTRODUÇÃO}

O envelhecimento, a urbanização, as mudanças sociais e econômicas impactam o modo de viver, trabalhar e se alimentar dos brasileiros. Nesse contexto, mudanças nos hábitos de alimentação e de vida, como o sedentarismo, a substituição de alimentos in natura ou minimamente processados, que deveriam ser a base de uma alimentação saudável, por produtos ultraprocessados, representam fatores de risco expressivos para o desenvolvimento de Doenças Crônicas Não Transmissíveis (DCNTs) (BRASIL, 2014).

Entre os idosos, a alimentação e os hábitos de vida saudáveis contribuem para uma melhor qualidade de vida e para o envelhecimento ativo, especialmente em indivíduos que já apresentam DCNTs, como hipertensão, diabetes tipo 2 e doenças cardiovasculares, entre outras (ORGANIZAÇÃO PAN-AMERICANA DA SAÚDE [OPAS], 2012), sendo que, em relação à alimentação, quanto maior o número de comorbidades maior a percepção de dificuldades para uma alimentação saudável (LINDEMANN; OLIVEIRA; MENDOZA-SASSI, 2016).

Além disso, os idosos representam um dos grupos etários de maior risco nutricional, principalmente pelas alterações fisiológicas que os acometem com o passar dos anos (OPAS, 2012). Assim, estratégias para conhecer a realidade alimentar e os fatores envolvidos são importantes a fim de possibilitar maior cuidado com a alimentação e hábitos de vida direcionados para a promoção da saúde.

Diante do exposto, o objetivo deste estudo foi descrever a frequência de consumo de alimentos classificados como saudáveis, processados e ultraprocessados e fatores relacionados aos hábitos alimentares e de vida de idosos.

\section{MÉTODOS}

Trata-se de um estudo transversal de natureza quantitativa, constituído por amostra de conveniência, proveniente de um Centro de Convivência do Idoso (CCI) de Campo Grande (Mato Grosso do Sul). Os CCls são vinculados à Secretaria Municipal de Assistência Social. As atividades desenvolvidas 
voltam-se para vivências em grupo, experimentações artísticas, culturais, esportivas e de lazer, e valorização das experiências vividas como forma de expressão, interação e proteção social, com o intuito de implementar atividades de convivência e fortalecimento de vínculos por meio de ações voltadas para características, interesses e demandas específicas dos idosos. Em Campo Grande, são quatro unidades que atendem idosos a partir de 60 anos, independente do local de residência e renda (CCl, 2019).

Todos os indivíduos, com idade igual ou superior a 60 anos, que frequentaram o espaço dedicado para atividades de integração e valorização da pessoa idosa durante o período da coleta de dados, foram convidados a participar. Foram excluídos indivíduos com dificuldade para responder com clareza aos questionamentos, identificada a partir da não compreensão das perguntas ou respostas imprecisas.

Para caracterização da amostra, foram investigadas as seguintes informações: sexo (registrado pela instituição), data de nascimento, situação conjugal, escolaridade e renda. Quanto aos hábitos relacionados à saúde, foram considerados: prática de atividade física, local, frequência semanal e qual a atividade/modalidade praticada; tabagismo (fumante atual, ex-fumante ou nunca fumou), presença de DCNTs diagnosticadas (por médico) e especificação da doença.

Para o consumo de alimentos, foi elaborado um formulário contendo alimentos e bebidas e suas respectivas frequências semanais de consumo, baseado nos grupos alimentares apresentados no Guia Alimentar para a População Brasileira, de 2008 (BRASIL, 2008), e, posteriormente, divididos em alimentos marcadores de uma alimentação saudável e alimentos processados/ultraprocessados, de acordo com o Guia Alimentar atualizado em 2014 (BRASIL, 2014). Esse questionário foi submetido a um pré-teste, a fim de verificar a compreensão em relação à frequência de consumo dos alimentos, considerando a seguinte distribuição de consumo: consumo no dia anterior; nunca ou raramente consome; frequência semanal ou não recorda. Para a análise final, as frequências de consumo foram categorizadas em: nunca ou raramente consome; $\leq 3$ vezes/semana; de 4 a 6 vezes/ semana; e todos os dias. O pré-teste foi realizado com idosos, de ambos os sexos, não pertencentes ao local de estudo, perfazendo $5 \%$ do universo de 
idosos possíveis de participarem do estudo (frequência semanal ao $\mathrm{CCl}$ de 500 idosos, segundo relato da instituição). Os idosos foram entrevistados individualmente, mantendo-se a mesma sequência de variáveis a ser adotada no estudo. Ao final do pré-teste, acrescentou-se a especificação para o tipo de diabetes (tipo 1 ou 2).

Os alimentos incluídos neste estudo foram classificados em duas categorias, sendo que foram incluídos os alimentos citados com maior frequência identificados no pré-teste: Marcadores de alimentação saudável (arroz integral; feijões, ervilhas e outras leguminosas; leite integral; leite semi ou desnatado; queijo frescal; iogurte natural; frutas in natura; folhosos in natura; legumes in natura; carnes frescas - bovina, suína e de aves; peixes; ovo cozido; oleaginosas e azeite); e alimentos processados/ ultraprocessados (macarrão instantâneo; salgados prontos industrializados; margarina; vegetais em conserva; linguiça; salsichas; mortadela; presunto; doces industrializados; achocolatados; refrigerantes; refrigerantes diet ou light e sucos industrializados). Os participantes foram entrevistados individualmente, tendo em vista o consumo dos últimos 30 dias.

Com o intuito de constatar o conhecimento prévio sobre o Guia Alimentar para a População Brasileira (BRASIL, 2014), os participantes foram questionados se o conheciam.

A associação entre as variáveis foi calculada pelo Teste Qui-quadrado utilizando-se o software Sigma Stat ${ }^{\circledR}$, versão 2.0, com nível de significância de $5 \%$.

Este estudo foi aprovado pelo Comitê de Ética em Pesquisa em Seres Humanos da Universidade Federal de Mato Grosso do Sul (CEP/UFMS). Todos os idosos manifestaram concordância de sua participação voluntária e anônima por meio da assinatura do Termo de Consentimento Livre e Esclarecido (TCLE).

\section{RESULTADOS E DISCUSSÃO}

Participaram deste estudo 152 idosos, sendo 126 (82,89\%) do sexo feminino, com idade média de 71,9 anos $( \pm 5,9)$. A idade das mulheres variou entre 60 e 70 anos, enquanto a dos homens, entre 63 e 85 anos, sendo iden- 
tificada associação entre o sexo e a faixa etária dos participantes $(p=0,01)$, com o sexo masculino mais prevalente que o feminino na classificação de idade $\geq 80$ anos, porém sem diferença entre as demais faixas etárias.

As informações referentes às variáveis sociodemográficas, tabagismo, consumo de álcool e atividade física são apresentadas na Tabela 1.

Tabela 1 - Características sociodemográficas e de hábitos de vida de uma amostra de idosos $(n=152)$ de um Centro de Convivência de Idosos, de acordo com o sexo, de Campo Grande, MS, 2017

\begin{tabular}{|c|c|c|c|c|c|}
\hline \multirow{3}{*}{ Variáveis } & \multicolumn{4}{|c|}{ Sexo } & \multirow{3}{*}{$\mathbf{p}$} \\
\hline & \multicolumn{2}{|c|}{$\begin{array}{c}\text { Masculino } \\
n=26\end{array}$} & \multicolumn{2}{|c|}{$\begin{array}{c}\text { Feminino } \\
n=126\end{array}$} & \\
\hline & $\mathbf{n}$ & $\%$ & $\mathbf{n}$ & $\%$ & \\
\hline
\end{tabular}

\section{Faixa etária}

até 69 anos

70 a 79 anos

$\geq 80$ anos

$\begin{array}{rrrrr}6 & 23,1^{\mathrm{a}} & 55 & 43,7^{\mathrm{a}} & \\ 14 & 53,8^{\mathrm{a}} & 63 & 50,0^{\mathrm{a}} & 0,01^{*} \\ 6 & 23,1^{\mathrm{a}} & 8 & 6,3^{\mathrm{b}} & \end{array}$

\section{Situação conjugal}

Casado/União estável

Solteiro/Separado/Viúvo

$\begin{array}{lllll}16 & 61,5^{\mathrm{a}} & 35 & 27,8^{\mathrm{b}} & \\ 10 & 38,5^{\mathrm{b}} & 91 & 72,2^{\mathrm{a}} & 0,002^{*}\end{array}$

\section{Escolaridade}

Analfabeto/Fundamental Incompleto

Fundamental completo

Ensino Médio completo/incompleto

Ensino Superior completo/incompleto

$\begin{array}{rrrrr}7 & 26,9 & 57 & 45,3 & \\ 8 & 30,8 & 27 & 21,4 & 0,28 \\ 5 & 19,2 & 25 & 19,8 & \\ 6 & 23,1 & 17 & 13,5 & \\ & & & & \\ 0 & 0,0^{a} & 14 & 11,11^{\text {a }} & \\ 17 & 65,4^{\text {a }} & 105 & 83,33^{\mathrm{a}} & <0,0001^{*} \\ 9 & 34,6^{\text {a }} & 7 & 5,56^{\mathrm{b}} & \end{array}$

\section{Renda Mensal (Salário Mínimo)}

Nenhum ou $<1$

1 a 3

$\geq 4$

\section{Tabagismo}

Nunca fumou

Ex-fumante/Fumante atual**

\section{Consumo de bebida alcoólica}

Não

$\begin{array}{lllll}12 & 46,2^{\mathrm{b}} & 94 & 74,6^{\mathrm{a}} & 0,008^{*} \\ 14 & 53,8^{\mathrm{a}} & 32 & 25,4^{\mathrm{b}}\end{array}$

Raramente

$\begin{array}{llll}18 & 69,3 & 88 & 69,8\end{array}$

Sim

$3 \quad 11,5 \quad 20 \quad 15,9$

0,74

$5 \quad 19,2 \quad 18 \quad 14,3$




\begin{tabular}{|c|c|c|c|c|c|}
\hline \multirow{3}{*}{ Variáveis } & \multicolumn{4}{|c|}{ Sexo } & \multirow{3}{*}{$\mathbf{p}$} \\
\hline & \multicolumn{2}{|c|}{$\begin{array}{c}\text { Masculino } \\
n=26\end{array}$} & \multicolumn{2}{|c|}{$\begin{array}{c}\text { Feminino } \\
n=126\end{array}$} & \\
\hline & $\mathbf{n}$ & $\%$ & $n$ & $\%$ & \\
\hline \multicolumn{6}{|l|}{ Prática de atividade física } \\
\hline Sim & 23 & 88,5 & 124 & 98,4 & \multirow{2}{*}{0,05} \\
\hline Não & 3 & 11,5 & 2 & 1,6 & \\
\hline \multicolumn{6}{|c|}{ Frequência semanal de atividade física } \\
\hline$<3$ vezes por semana & $22^{\mathrm{a}}$ & 84,6 & $5^{b}$ & 4,0 & \multirow{2}{*}{$<0,0001^{*}$} \\
\hline$\geq 3$ vezes por semana & $1^{\mathrm{b}}$ & 3,9 & $119^{a}$ & 94,4 & \\
\hline \multicolumn{6}{|l|}{ Modalidade de atividade física } \\
\hline Dança & 2 & 7,7 & 7 & 5,6 & \multirow{4}{*}{0,29} \\
\hline Ginástica/alongamento/Pilates & 5 & 19,2 & 25 & 19,8 & \\
\hline Hidroginástica/natação & 13 & 50,1 & 87 & 69,0 & \\
\hline Vôlei/bocha/caminhada & 3 & 11,5 & 5 & 3,97 & \\
\hline
\end{tabular}

Nota: As letras nas linhas indicam as diferenças estatisticamente calculadas.

* Teste Qui-quadrado $(p<0,05)$; ** Fumante atual está relacionado a apenas um indivíduo do sexo masculino.

Fonte: As autoras (2017).

$\mathrm{Na}$ amostra pesquisada, constatou-se maior participação das muIheres como frequentadoras do $\mathrm{CCl}$. Em Florianópolis, a longevidade feminina também mostrou-se presente,pois um número expressivo de mulheres participavam de grupos de convivência, uma vez que, do total de mulheres ( $n=266$ ), 59,8\% eram mulheres e viúvas (BENEDETTI; MAZO; BORGES, 2012).

Nesse contexto, destaca-se também a resistência masculina para frequentar espaços de convivência em grupo. Em um estudo realizado na Paraíba, as mulheres casadas, quando questionadas sobre seus esposos, responderam que, por preconceito, eles não as acompanhavam aos encontros dos grupos de convivência (ANDRADE et al., 2014). Além disso, as mulheres demonstram maior atenção com a saúde e com o autocuidado, além de buscarem maior convívio social, enquanto os homens participam com menor frequência de ações coletivas por questões socioculturais (SILVA et al., 2011). 
Ao avaliar o estado civil de 126 participantes do sexo feminino, 72,2\% relataram situação conjugal solteira, separada ou viúva, sendo que apresentar união estável e/ou casamento esteve associado ao sexo masculino, enquanto o sexo feminino esteve associado com a situação separada, viúva e solteira, sendo esta última categoria presente somente neste sexo $(p=0,002)$. Nesse cenário salienta-se a feminização da velhice, ou seja, pelo predomínio de mulheres na população idosa (SALGADO, 2002), pelo fato de os homens ainda viverem menos que as mulheres (MESSIAS, 2012). Com isso, verifica-se também a presença de doenças associadas às modificações psicológicas que refletem a adaptação que o ser humano vivencia diante de perdas de vínculos, por distanciamentos ou morte, que poderão repercutir no desenvolvimento da depressão. Diversos fatores relacionam-se com o surgimento de sintomas depressivos na mulher idosa, como a solidão, aposentadoria, abandono familiar, isolamento social, perda do cônjuge ou companheiro, sendo que tais situações contribuem para a maior vulnerabilidade entre as mulheres (SALES et al., 2016). Por outro lado, possivelmente os fatores relatados podem influenciar também a maior participação das mulheres em grupos de convivência, com o intuito de superar/amenizar as situações citadas.

Sobre a escolaridade não houve diferença entre os sexos $(p=0,28)$. A resposta mais frequente entre as mulheres foi analfabeto/fundamental incompleto e, entre os homens, fundamental completo.

Quanto à análise da renda, foi significativa a associação entre o sexo masculino e renda superior a 4 salários, chegando a até 30 salários mínimos $(p<0,0001)$. Contudo a maioria dos participantes $(80,26 \%)$, de ambos os sexos, relatou renda mensal entre 1 e 3 salários mínimos. Esse estrato de renda entre 1 e 3 salários mínimos também foi mais frequente no trabalho realizado por Carvalho et al. (2017), no qual 65,8\% dos idosos foram classificados nesse intervalo. No que diz respeito à repercussão da renda na vida do idoso, sabe-se que, nessa fase da vida, as doenças crônicas manifestam-se com expressiva frequência e, muitas vezes, mais de uma doença concomitantemente, o que implica o uso dos recursos financeiros para o tratamento medicamentoso de tais condições. Assim, a limitação orçamentária pode comprometer a aquisição de alimentos e, consequentemente, levar à in- 
segurança alimentar (BUSATO et al., 2014), com implicações quantitativas e qualitativas na alimentação diária, com risco de comprometimento do estado nutricional em curto prazo.

O hábito de nunca ter fumado associou-se $(p<0,008)$ ao sexo feminino. Ainda, nota-se que $46,2 \%$ dos homens e $74,6 \%$ das mulheres afirmaram nunca ter fumado. Entre idosos, o hábito de fumar, de acordo com Silva et al. (2017), mostra-se maior entre os homens. Segundo o inquérito nacional Vigilância de Fatores de Risco e Proteção para Doenças Crônicas por Inquérito Telefônico (Vigitel), o percentual de fumantes entre indivíduos com idades entre 55 e 64 anos foi de 15,2\% para o sexo masculino e 10,2\% para o feminino. A partir dos 65 anos ou mais, o percentual foi de $7,2 \%$ para homens e 5,4\% para as mulheres (BRASIL, 2019).

Ao compararmos os percentuais da referida pesquisa publicados em 2018 (BRASIL, 2018) e 2019 (BRASIL, 2019) nota-se um aumento no percentual de homens que relataram fumar, sendo em 2018 de 12,8\% e em 2019, 15,2\%, na faixa de idade entre 55 e 64 anos. Para homens e mulheres com idade a partir de 65 anos é possível notar redução nos percentuais, entre os homens, de 9,6\% para 7,2\% e, entre as mulheres, de $5,8 \%$ para $5,4 \%$.

No presente estudo, apenas um participante do sexo masculino mencionou ser fumante atual, porém $50 \%$ dos homens e $24,6 \%$ das mulheres afirmaram serem ex-fumantes, denotando maior frequência desse hábito entre os homens. Independentemente do número de indivíduos fumantes, cabe registrar que o hábito de fumar não só aumenta o risco para doenças como o câncer de pulmão, mas também está negativamente relacionado a fatores que podem levar a importantes perdas da capacidade funcional, além de acelerar a taxa de diminuição da densidade óssea, da força muscular e da função respiratória (WORLD HEALTH ORGANIZATION, 2005).

Ainda com relação aos fatores de riscos à saúde, aproximadamente $70 \%$ da amostra mencionou não consumir bebidas alcoólicas. Não foi constatada diferença entre os sexos, contudo o consumo foi mencionado com maior frequência entre os homens. Nesse sentido, estudo realizado por Luís et al. (2018), o qual, ao considerar um dos instrumentos para classificação do risco do consumo de álcool, identificou, entre os que mencionaram uso do 
álcool, consumo de risco por $60 \%$ dos idosos. Os autores citados ressaltam a relevância de rastreamento do uso de álcool entre idosos, visando, quando necessário, a estratégias de tratamento. Também ressaltam a necessidade de investigação de forma sistemática do uso de substâncias como o álcool, especialmente por tratar-se de indivíduos com possibilidade de manifestação de uma ou mais patologias.

Cabe ressaltar que os idosos são mais vulneráveis ao uso de álcool, bem como ao de tabaco, e esses comportamentos poderão representar proporções importantes já que o número de idosos eleva-se progressivamente em todo o mundo. Nesse estágio de vida, o uso de diversos medicamentos de forma concomitante, combinado com as substâncias presentes no álcool, torna o indivíduo susceptível a interações, com respectivo agravamento do quadro clínico, dificuldade de recuperação e de interação social (BARBOSA et al., 2018).

Martins et al. (2016) verificaram associação significativa entre o sexo masculino e consumo de risco de álcool. Além disso, afirmam que o abuso de álcool é um conceito global que inclui desde o consumo de risco até a dependência, e são poucos os estudos que avaliam diretamente o consumo de risco do álcool no idoso. É importante ressaltar que o uso nocivo de álcool contribui para o desenvolvimento de mais de 200 doenças, incluindo alguns tipos de câncer, infecções e transtornos mentais (PAN AMERICAN HEALTH ORGANIZATION, 2015).

No que se refere à prática de atividade física, não foi constatada diferença entre os sexos, porém a frequência semanal $\geq 3$ dias esteve associada ao sexo feminino $(p<0,0001)$, independente da modalidade $(p=0,29)$. Para o sexo feminino, 94,4\% afirmaram praticar atividade física com frequência $\geq 3 x$ na semana. Dentre os participantes do sexo masculino, apenas 3,9\% relataram essa prática com frequência $\geq 3 x$ na semana.

A maioria dos idosos (97\%) relatou praticar atividade física no $\mathrm{CCl}$. Dessa forma, assume-se como um local de extrema importância para o estímulo ao envelhecimento ativo, contribuindo para a prática de atividades físicas e interação social. Porém ainda é necessário expressivo incentivo, principalmente para o sexo masculino, visto que aderem à atividade física com menor frequência semanal. 
Botton, Cúnico e Strey (2017) sugerem que, além dos homens não serem educados para a prática do autocuidado, a vulnerabilidade imposta às mulheres traz o aprendizado do cuidado com a própria saúde de forma rotineira. Ainda, Silva e Menandro (2014) afirmam que a mulher foi determinada para cuidar da saúde de toda a família, enquanto que os homens apreenderam que deveriam deixar de lado hábitos saudáveis, tal como a preocupação com a saúde, a fim de manter sua masculinidade e dedicando-se ao provimento do lar por meio do trabalho.

Especificamente em relação à prática regular de atividade física por idosos, compreendida como um fator importante para a saúde nessa fase da vida, destacam-se os resultados de Santana et al. (2015). Os autores demonstraram possível efeito da prática de atividade física na diminuição do risco coronariano nessa população, em ambos os sexos, o que indica a atividade física como uma estratégia universal de combate às DCNTs.

No que diz respeito à alimentação, na Tabela 2, são apresentadas as frequências de consumo semanal de alimentos marcadores de uma alimentação saudável. Destacamos que não houve diferença entre idosos do sexo masculino e feminino em relação à frequência de consumo semanal para esse grupo de alimentos ( $p>0,05)$. 
Tabela 2 - Frequência semanal de consumo de alimentos marcadores de uma alimentação saudável, de uma amostra de idosos ( $n=152)$, de acordo com o sexo, de Campo Grande, MS, 2017

\begin{tabular}{|c|c|c|c|c|c|c|c|c|c|}
\hline \multirow{3}{*}{ Alimentos } & \multicolumn{8}{|c|}{$\begin{array}{l}\text { Frequência de consumo semanal } \\
\qquad \mathrm{n}(\%)\end{array}$} & \multirow{3}{*}{$\mathbf{p}$} \\
\hline & \multicolumn{4}{|c|}{$\begin{array}{l}\text { Masculino } \\
n=26\end{array}$} & \multicolumn{4}{|c|}{$\begin{array}{c}\text { Feminino } \\
\mathrm{n}=126\end{array}$} & \\
\hline & $\begin{array}{l}\text { Nunca/ } \\
\text { Rara- } \\
\text { mente } \\
\text { consome }\end{array}$ & $\begin{array}{c}\leq 3 \\
\text { vezes }\end{array}$ & $\begin{array}{l}4 \text { a } 6 \\
\text { vezes }\end{array}$ & $\begin{array}{l}\text { Todos } \\
\text { os dias }\end{array}$ & $\begin{array}{c}\text { Nunca/ } \\
\text { Rara- } \\
\text { mente } \\
\text { Consome }\end{array}$ & $\begin{array}{c}\leq 3 \\
\text { vezes }\end{array}$ & $\begin{array}{l}4 \text { a } 6 \\
\text { vezes }\end{array}$ & $\begin{array}{l}\text { Todos } \\
\text { os dias }\end{array}$ & \\
\hline $\begin{array}{l}\text { Arroz inte- } \\
\text { gral }\end{array}$ & $\begin{array}{r}21 \\
(80,8)\end{array}$ & $\begin{array}{r}2 \\
(7,7)\end{array}$ & $\begin{array}{r}2 \\
(7,7)\end{array}$ & $\begin{array}{r}1 \\
(3,8)\end{array}$ & $\begin{array}{r}94 \\
(74,6)\end{array}$ & $\begin{array}{r}11 \\
(8,7)\end{array}$ & $\begin{array}{r}8 \\
(6,3)\end{array}$ & $\begin{array}{r}13 \\
(10,3)\end{array}$ & 0,76 \\
\hline Feijões & $\begin{array}{r}2 \\
(7,7)\end{array}$ & $\begin{array}{r}0 \\
(0,0)\end{array}$ & $\begin{array}{r}1 \\
(3,8)\end{array}$ & $\begin{array}{r}23 \\
(88,5)\end{array}$ & $\begin{array}{r}16 \\
(12,7)\end{array}$ & $\begin{array}{r}19 \\
(15,1)\end{array}$ & $\begin{array}{r}10 \\
(7,9)\end{array}$ & $\begin{array}{r}81 \\
(64,3)\end{array}$ & 0,08 \\
\hline $\begin{array}{l}\text { Ervilhas e } \\
\text { outras legu- } \\
\text { minosas }\end{array}$ & $\begin{array}{r}23 \\
(88,5)\end{array}$ & $\begin{array}{r}3 \\
(11,5)\end{array}$ & $\begin{array}{r}0 \\
(0,0)\end{array}$ & $\begin{array}{r}0 \\
(0,0)\end{array}$ & $\begin{array}{r}105 \\
(83,3)\end{array}$ & $\begin{array}{r}21 \\
(16,7)\end{array}$ & $\begin{array}{r}0 \\
(0,0)\end{array}$ & $\begin{array}{r}0 \\
(0,0)\end{array}$ & 0,52 \\
\hline $\begin{array}{l}\text { Leite inte- } \\
\text { gral }\end{array}$ & $\begin{array}{r}6 \\
(23,1)\end{array}$ & $\begin{array}{r}3 \\
(11,5)\end{array}$ & $\begin{array}{r}2 \\
(7,7)\end{array}$ & $\begin{array}{r}15 \\
(57,5)\end{array}$ & $\begin{array}{r}54 \\
(42,9)\end{array}$ & $\begin{array}{r}10 \\
(7,9)\end{array}$ & $\begin{array}{r}6 \\
(4,8)\end{array}$ & $\begin{array}{r}56 \\
(44,4)\end{array}$ & 0,31 \\
\hline $\begin{array}{l}\text { Leite semi } \\
\text { ou desna- } \\
\text { tado }\end{array}$ & $\begin{array}{r}23 \\
(88,5)\end{array}$ & $\begin{array}{r}0 \\
(0,0)\end{array}$ & $\begin{array}{r}1 \\
(3,8)\end{array}$ & $\begin{array}{r}2 \\
(7,7)\end{array}$ & $\begin{array}{r}94 \\
(74,6)\end{array}$ & $\begin{array}{r}13 \\
(10,3)\end{array}$ & $\begin{array}{r}2 \\
(1,6)\end{array}$ & $\begin{array}{r}17 \\
(13,5)\end{array}$ & 0,23 \\
\hline $\begin{array}{l}\text { Queijo fres- } \\
\text { cal }\end{array}$ & $\begin{array}{r}14 \\
(53,8)\end{array}$ & $\begin{array}{r}7 \\
(26,9)\end{array}$ & $\begin{array}{r}4 \\
(15,4)\end{array}$ & $\begin{array}{r}1 \\
(3,8)\end{array}$ & $\begin{array}{r}61 \\
(48,4)\end{array}$ & $\begin{array}{r}28 \\
(22,2)\end{array}$ & $\begin{array}{r}15 \\
(11,9)\end{array}$ & $\begin{array}{r}22 \\
(17,5)\end{array}$ & 0,36 \\
\hline $\begin{array}{l}\text { logurte na- } \\
\text { tural }\end{array}$ & $\begin{array}{r}23 \\
(88,5)\end{array}$ & $\begin{array}{r}0 \\
(0,0)\end{array}$ & $\begin{array}{r}0 \\
(0,0)\end{array}$ & $\begin{array}{r}3 \\
(11,5)\end{array}$ & $\begin{array}{r}108 \\
(85,7)\end{array}$ & $\begin{array}{r}14 \\
(11,1)\end{array}$ & $\begin{array}{r}1 \\
(0,8)\end{array}$ & $\begin{array}{r}3 \\
(2,4)\end{array}$ & 0,05 \\
\hline $\begin{array}{l}\text { Frutas } \\
\text { in natura }\end{array}$ & $\begin{array}{r}0 \\
(0,0)\end{array}$ & $\begin{array}{r}5 \\
(19,2)\end{array}$ & $\begin{array}{r}1 \\
(3,8)\end{array}$ & $\begin{array}{r}20 \\
(76,9)\end{array}$ & $\begin{array}{r}2 \\
(1,6)\end{array}$ & $\begin{array}{r}15 \\
(11,9)\end{array}$ & $\begin{array}{r}5 \\
(4,0)\end{array}$ & $\begin{array}{r}104 \\
(82,5)\end{array}$ & 0,71 \\
\hline $\begin{array}{l}\text { Folhosos } \\
\text { in natura }\end{array}$ & $\begin{array}{r}2 \\
(7,7)\end{array}$ & $\begin{array}{r}4 \\
(15,4)\end{array}$ & $\begin{array}{r}6 \\
(23,1)\end{array}$ & $\begin{array}{r}14 \\
(53,8)\end{array}$ & $\begin{array}{r}4 \\
(3,2)\end{array}$ & $\begin{array}{r}23 \\
(18,3)\end{array}$ & $\begin{array}{r}14 \\
(1,11)\end{array}$ & $\begin{array}{r}85 \\
(67,5)\end{array}$ & 0,24 \\
\hline $\begin{array}{l}\text { Legumes } \\
\text { in natura }\end{array}$ & $\begin{array}{r}0 \\
(0,0)\end{array}$ & $\begin{array}{r}7 \\
(26,9)\end{array}$ & $\begin{array}{r}4 \\
(15,4)\end{array}$ & $\begin{array}{r}15 \\
(57,5)\end{array}$ & $\begin{array}{r}5 \\
(4,0)\end{array}$ & $\begin{array}{r}25 \\
(19,8)\end{array}$ & $\begin{array}{r}15 \\
(11,9)\end{array}$ & $\begin{array}{r}81 \\
(64,3)\end{array}$ & 0,59 \\
\hline $\begin{array}{l}\text { Carnes fres- } \\
\text { cas }\end{array}$ & $\begin{array}{r}0 \\
(0,0)\end{array}$ & $\begin{array}{r}1 \\
(3,8)\end{array}$ & $\begin{array}{r}2 \\
(7,7)\end{array}$ & $\begin{array}{r}23 \\
(88,5)\end{array}$ & $\begin{array}{r}2 \\
(1,6)\end{array}$ & $\begin{array}{r}19 \\
(15,1)\end{array}$ & $\begin{array}{r}20 \\
(15,9)\end{array}$ & $\begin{array}{r}85 \\
(67,5)\end{array}$ & 0,19 \\
\hline Peixes & $\begin{array}{r}15 \\
(57,5)\end{array}$ & $\begin{array}{r}10 \\
(38,5)\end{array}$ & $\begin{array}{r}1 \\
(3,8)\end{array}$ & $\begin{array}{r}0 \\
(0,0)\end{array}$ & $\begin{array}{r}68 \\
(54,0)\end{array}$ & $\begin{array}{r}57 \\
(45,2)\end{array}$ & $\begin{array}{r}1 \\
(0,8)\end{array}$ & $\begin{array}{r}0 \\
(0,0)\end{array}$ & 0,40 \\
\hline Ovo cozido & $\begin{array}{r}11 \\
(42,3)\end{array}$ & $\begin{array}{r}9 \\
(34,6)\end{array}$ & $\begin{array}{r}2 \\
(7,7)\end{array}$ & $\begin{array}{r}4 \\
(15,4)\end{array}$ & $\begin{array}{r}54 \\
(42,9)\end{array}$ & $\begin{array}{r}54 \\
(42,9)\end{array}$ & $\begin{array}{r}10 \\
(7,9)\end{array}$ & $\begin{array}{r}8 \\
(6,3)\end{array}$ & 0,46 \\
\hline Oleaginosas & $\begin{array}{r}19 \\
(73,1)\end{array}$ & $\begin{array}{r}4 \\
(15,4)\end{array}$ & $\begin{array}{r}0 \\
(0,0)\end{array}$ & $\begin{array}{r}3 \\
(11,5)\end{array}$ & $\begin{array}{r}98 \\
(77,8)\end{array}$ & $\begin{array}{r}10 \\
(7,9)\end{array}$ & $\begin{array}{r}3 \\
(2,4)\end{array}$ & $\begin{array}{r}15 \\
(11,9)\end{array}$ & 0,58 \\
\hline Azeite & $\begin{array}{r}10 \\
(38,5) \\
\end{array}$ & $\begin{array}{r}3 \\
(11,5) \\
\end{array}$ & $\begin{array}{r}2 \\
(7,7) \\
\end{array}$ & $\begin{array}{r}11 \\
(42,3) \\
\end{array}$ & $\begin{array}{r}40 \\
(31,7) \\
\end{array}$ & $\begin{array}{r}11 \\
(8,7) \\
\end{array}$ & $\begin{array}{r}9 \\
(7,1) \\
\end{array}$ & $\begin{array}{r}66 \\
(52,4) \\
\end{array}$ & 0,82 \\
\hline
\end{tabular}

* Teste Qui-quadrado $(p<0,05)$.

Fonte: As autoras (2017). 
Considerando a distribuição percentual dos alimentos consumidos, algumas constatações mostram-se relevantes, como por exemplo, o consumo de leite. Mostrou-se mais frequente o consumo do leite integral quando comparado ao semidesnatado ou desnatado para ambos os sexos. Dos participantes que afirmaram consumo diário de leites, 46,7\% relataram consumo dos integrais, e apenas 12,5\% mencionaram consumo diário de semidesnatados ou desnatados.

Sobre os benefícios nutricionais do leite e derivados para a população idosa, o consumo de alimentos lácteos favorece principalmente o adequado metabolismo ósseo, contribui para o consumo proteico e também proporciona efeitos satisfatórios relacionados à imunidade, massa magra e microbiota intestinal. Assim, justifica-se a importância da introdução desse grupo de alimentos de maneira regular e adequada quantitativamente na dieta (FERREIRA et al., 2017).

Outro alimento importante devido ao seu conteúdo nutricional e considerado tradicional na alimentação da população brasileira é o feijão. Segundo o Guia Alimentar (BRASIL, 2014), quando combinado com arroz ou outro cereal, tem-se uma fonte de proteína de excelente qualidade. Neste estudo, o consumo diário de feijão foi maior para os homens $(88,5 \%)$ do que para as mulheres (64,3\%).

Ao compararmos a frequência de consumo de feijão com os dados obtidos pela Vigitel, os quais representam um conjunto de resultados de 26 capitais do nosso país e do Distrito Federal, a frequência do consumo de feijão em cinco ou mais dias da semana, entre indivíduos de Campo Grande, com idade superior a 65 anos, mostrou-se maior entre homens $(65,4 \%)$ do que entre mulheres (54,4\%). A média nacional foi de 58,7\% na faixa de idade citada (BRASIL, 2018). Na publicação de 2019 (BRASIL, 2019) não foi analisado o consumo de feijão separadamente. Na amostra estudada, a frequência diária de consumo de feijão maior do que a média nacional pode estar relacionada ao fato de que mesmo sendo uma capital, o que poderia representar consumo de alimentos prontos para o consumo ou mesmo preparações diversificadas, com influências de diversas culturas alimentares, e especificamente para o estágio de vida investigado, os in- 
divíduos ainda conservam hábitos alimentares tradicionais, como o típico arroz com feijão.

Sobre alimentos fontes de proteínas, além das carnes de origem bovina, suína ou de aves, destaca-se o consumo de peixes. Neste trabalho, $57,5 \%$ e $54 \%$ dos homens e mulheres, respectivamente, mencionaram não consumir ou raramente consumir peixe. O Ministério da Saúde recomenda consumir peixe fresco pelo menos duas vezes por semana (BRASIL, 2009), porém é importante ressaltar que o custo desse alimento, muitas vezes, supera em três a quatro vezes o valor da carne bovina, suína ou de frango e, com isso, consumir peixes com frequência semanal torna-se inviável para muitas famílias, além de relacionar-se diretamente aos hábitos culturais da região/família.

Quanto ao consumo de folhosos in natura, observou-se maior consumo diário entre as mulheres (67,5\%). Nesse mesmo grupo de alimentos vegetais in natura, observou-se consumo diário de legumes com maior frequência entre as mulheres $(64,3 \%)$ do que entre os homens $(57,5 \%)$. Uma possível justificativa para essa diferença de consumo pode ser decorrente da necessidade de maior trabalho para preparar legumes e guarnições (cortar, picar, refogar) e, para os homens que residirem sozinhos, não representar motivação para o preparo. Salienta-se que esse grupo de alimentos impacta na ingestão de vitaminas, minerais e fibras, cujos valores variam de acordo com o alimento e que podem ser confirmados em tabelas de composição nutricional (TABELA DE COMPOSIÇÃO QUÍMICA DOS ALIMENTOS, 2016).

Sobre o consumo de frutas in natura, observou-se que $76,9 \%$ dos homens e $82,5 \%$ das mulheres afirmaram consumir todos os dias, contudo cabe lembrar que não foi investigada a quantidade diária consumida. Por outro lado, destacam-se as proporções de idosos que relataram consumo semanal inferior a 3x/semana (19,2\% e 11,9\%, respectivamente, para homens e mulheres). Vale ressaltar, principalmente por expressarem resultados representativos da população brasileira, que, segundo a Vigitel, de 2019, que o consumo do grupo de frutas e hortaliças em cinco ou mais dias da semana aumenta com o passar dos anos, alcançando 35,3\% entre 
os homens e $46,5 \%$ entre as mulheres com 65 anos ou mais, quando comparado com as faixas de idade mais jovens, a partir de 18anos. Em Campo Grande, MS, independente da idade, 29,3\% dos homens e 40,3\% das muIheres relataram consumo em cinco ou mais dias da semana (BRASIL, 2019). Destaca-se que a formação dos hábitos alimentares inicia-se na infância, perpetuando-se ao longo dos anos, o que refletirá na sua consolidação na vida adulta.

A Organização Mundial da Saúde (OMS) baseia-se em evidências de que o consumo de frutas, legumes e verduras reduz o risco de doenças cardiovasculares, câncer, diabetes tipo 2 e obesidade. A partir disso, recomenda-se um consumo mínimo de pelo menos cinco porções diárias de frutas, legumes e verduras, o que equivale a $400 \mathrm{~g}$ ou mais por dia, sendo possível assim assegurar quantidade adequada da maioria dos micronutrientes, fibras e outras substâncias essenciais ao organismo (WORLD HEALTH ORGANIZATION, 2003).

Na Tabela 3, são apresentadas as frequências de consumo de alimentos processados e ultraprocessados. Constatou-se associação significativa em relação ao sexo feminino e a menor frequência de consumo de alimentos processados ou ultraprocessados, identificados na categoria não come ou raramente come, para linguiça $(p=0,004)$, salsichas $(p=0,03)$, mortadela $(p=0,01)$, presunto $(p=0,0008)$ e doces industrializados $(p=0,01)$. 
Tabela 3 - Frequência de consumo semanal de alimentos processados e ultraprocessados de uma amostra de idosos ( $n=152)$, de acordo com o sexo, de Campo Grande, MS, 2017

\begin{tabular}{|c|c|c|c|c|c|c|c|c|c|}
\hline \multirow[b]{3}{*}{ Alimentos } & \multicolumn{8}{|c|}{ Frequência de consumo semanal - $n(\%)$} & \multirow[b]{3}{*}{$\mathbf{p}$} \\
\hline & \multicolumn{4}{|c|}{$\begin{array}{c}\text { Masculino } \\
\mathrm{n}=26\end{array}$} & \multicolumn{4}{|c|}{$\begin{array}{c}\text { Feminino } \\
n=126\end{array}$} & \\
\hline & $\begin{array}{c}\text { Nunca/ } \\
\text { Rara- } \\
\text { mente } \\
\text { consome }\end{array}$ & $\begin{array}{c}\leq 3 \\
\text { vezes }\end{array}$ & $\begin{array}{c}4 \text { a } 6 \\
\text { vezes }\end{array}$ & $\begin{array}{l}\text { Todos } \\
\text { os dias }\end{array}$ & $\begin{array}{c}\text { Nunca/ } \\
\text { Rara- } \\
\text { mente } \\
\text { consome }\end{array}$ & $\begin{array}{c}\leq 3 \\
\text { vezes }\end{array}$ & $\begin{array}{l}4 \text { a } 6 \\
\text { vezes }\end{array}$ & $\begin{array}{l}\text { Todos } \\
\text { os } \\
\text { dias }\end{array}$ & \\
\hline $\begin{array}{l}\text { Macarrão } \\
\text { instantâneo }\end{array}$ & $\begin{array}{r}21 \\
(80,8)\end{array}$ & $\begin{array}{r}2 \\
(7,7)\end{array}$ & $\begin{array}{r}1 \\
(3,8)\end{array}$ & $\begin{array}{r}2 \\
(7,7)\end{array}$ & $\begin{array}{r}119 \\
(94,4)\end{array}$ & $\begin{array}{r}5 \\
(4,0)\end{array}$ & $\begin{array}{r}1 \\
(0,8)\end{array}$ & $\begin{array}{r}1 \\
(0,8)\end{array}$ & 0,05 \\
\hline $\begin{array}{l}\text { Salgados } \\
\text { prontos in- } \\
\text { dustrializados }\end{array}$ & $\begin{array}{r}21 \\
(80,8)\end{array}$ & $\begin{array}{r}2 \\
(7,7)\end{array}$ & $\begin{array}{r}2 \\
(7,7)\end{array}$ & $\begin{array}{r}1 \\
(3,8)\end{array}$ & $\begin{array}{r}110 \\
(87,3)\end{array}$ & $\begin{array}{r}12 \\
(9,5)\end{array}$ & $\begin{array}{r}2 \\
(1,6)\end{array}$ & $\begin{array}{r}2 \\
(1,6)\end{array}$ & 0,28 \\
\hline Margarina & $\begin{array}{r}17 \\
(65,4)\end{array}$ & $\begin{array}{r}3 \\
(11,5)\end{array}$ & $\begin{array}{r}0 \\
(0,0)\end{array}$ & $\begin{array}{r}6 \\
(23,1)\end{array}$ & $\begin{array}{r}90 \\
(71,4)\end{array}$ & $\begin{array}{r}11 \\
(8,7)\end{array}$ & $\begin{array}{r}6 \\
(4,8)\end{array}$ & $\begin{array}{r}1 \\
(15,1)\end{array}$ & 0,50 \\
\hline $\begin{array}{l}\text { Vegetais em } \\
\text { conserva }\end{array}$ & $\begin{array}{r}22 \\
(84,6)\end{array}$ & $\begin{array}{r}3 \\
(11,5)\end{array}$ & $\begin{array}{r}1 \\
(3,8)\end{array}$ & $\begin{array}{r}0 \\
(0,0)\end{array}$ & $\begin{array}{r}116 \\
(92,1)\end{array}$ & $\begin{array}{r}9 \\
(7,1)\end{array}$ & $\begin{array}{r}1 \\
(0,8)\end{array}$ & $\begin{array}{r}0 \\
(0,0)\end{array}$ & 0,34 \\
\hline Linguiça & $\begin{array}{r}15 \\
(57,7)\end{array}$ & $\begin{array}{r}10 \\
(38,5)\end{array}$ & $\begin{array}{r}1 \\
(3,8)\end{array}$ & $\begin{array}{r}0 \\
(0,0)\end{array}$ & $\begin{array}{r}104 \\
(82,5)\end{array}$ & $\begin{array}{r}22 \\
(17,5)\end{array}$ & $\begin{array}{r}0 \\
(0,0)\end{array}$ & $\begin{array}{r}0 \\
(0,0)\end{array}$ & $0,004^{*}$ \\
\hline Salsichas & $\begin{array}{r}23 \\
(88,5)\end{array}$ & $\begin{array}{r}3 \\
(11,5)\end{array}$ & $\begin{array}{r}0 \\
(0,0)\end{array}$ & $\begin{array}{r}0 \\
(0,0)\end{array}$ & $\begin{array}{r}123 \\
(97,6)\end{array}$ & $\begin{array}{r}3 \\
(2,4)\end{array}$ & $\begin{array}{r}0 \\
(0,0)\end{array}$ & $\begin{array}{r}0 \\
(0,0)\end{array}$ & $0,03^{*}$ \\
\hline Mortadela & $\begin{array}{r}18 \\
(69,2)\end{array}$ & $\begin{array}{r}7 \\
(26,9)\end{array}$ & $\begin{array}{r}1 \\
(3,8)\end{array}$ & $\begin{array}{r}0 \\
(0,0)\end{array}$ & $\begin{array}{r}114 \\
(90,5)\end{array}$ & $\begin{array}{r}11 \\
(8,7)\end{array}$ & $\begin{array}{r}1 \\
(0,8)\end{array}$ & $\begin{array}{r}0 \\
(0,0)\end{array}$ & $0,01^{*}$ \\
\hline Presunto & $\begin{array}{r}18 \\
(69,2)\end{array}$ & $\begin{array}{r}5 \\
(19,2)\end{array}$ & $\begin{array}{r}2 \\
(7,7)\end{array}$ & $\begin{array}{r}1 \\
(3,8)\end{array}$ & $\begin{array}{r}117 \\
(92,9)\end{array}$ & $\begin{array}{r}7 \\
(5,6)\end{array}$ & $\begin{array}{r}0 \\
(0,0)\end{array}$ & $\begin{array}{r}2 \\
(1,6)\end{array}$ & $0,0008 *$ \\
\hline $\begin{array}{l}\text { Doces indus- } \\
\text { trializados }\end{array}$ & $\begin{array}{r}9 \\
(34,6)\end{array}$ & $\begin{array}{r}8 \\
(30,8)\end{array}$ & $\begin{array}{r}5 \\
(19,2)\end{array}$ & $\begin{array}{r}4 \\
(15,4)\end{array}$ & $\begin{array}{r}71 \\
(56,3)\end{array}$ & $\begin{array}{r}41 \\
(32,5)\end{array}$ & $\begin{array}{r}5 \\
(4,0)\end{array}$ & $\begin{array}{r}9 \\
(7,1)\end{array}$ & 0,01 \\
\hline $\begin{array}{l}\text { Achocola- } \\
\text { tado }\end{array}$ & $\begin{array}{r}19 \\
(73,1)\end{array}$ & $\begin{array}{r}2 \\
(7,7)\end{array}$ & $\begin{array}{r}1 \\
(3,8)\end{array}$ & $\begin{array}{r}4 \\
(15,4)\end{array}$ & $\begin{array}{r}114 \\
(90,5)\end{array}$ & $\begin{array}{r}5 \\
(4,0)\end{array}$ & $\begin{array}{r}2 \\
(1,6)\end{array}$ & $\begin{array}{r}5 \\
(4,0)\end{array}$ & 0,08 \\
\hline Refrigerante & $\begin{array}{r}21 \\
(80,8)\end{array}$ & $\begin{array}{r}5 \\
(19,2)\end{array}$ & $\begin{array}{r}0 \\
(0,0)\end{array}$ & $\begin{array}{r}0 \\
(0,0)\end{array}$ & $\begin{array}{r}114 \\
(90,5)\end{array}$ & $\begin{array}{r}12 \\
(9,5)\end{array}$ & $\begin{array}{r}0 \\
(0,0)\end{array}$ & $\begin{array}{r}0 \\
(0,0)\end{array}$ & 0,15 \\
\hline $\begin{array}{l}\text { Refrigerante } \\
\text { diet ou light }\end{array}$ & $\begin{array}{r}26 \\
(100,0)\end{array}$ & $\begin{array}{r}0 \\
(0,0)\end{array}$ & $\begin{array}{r}0 \\
(0,0)\end{array}$ & $\begin{array}{r}0 \\
(0,0)\end{array}$ & $\begin{array}{r}124 \\
(98,4)\end{array}$ & $\begin{array}{r}2 \\
(1,6)\end{array}$ & $\begin{array}{r}0 \\
(0,0)\end{array}$ & $\begin{array}{r}0 \\
(0,0)\end{array}$ & 0,52 \\
\hline $\begin{array}{l}\text { Sucos indus- } \\
\text { trializados ou } \\
\text { em pó }\end{array}$ & $\begin{array}{r}21 \\
(80,8)\end{array}$ & $\begin{array}{r}2 \\
(7,7)\end{array}$ & $\begin{array}{r}2 \\
(7,7)\end{array}$ & $\begin{array}{r}1 \\
(3,8)\end{array}$ & $\begin{array}{r}105 \\
(83,3)\end{array}$ & $\begin{array}{r}1 \\
(11,9)\end{array}$ & $\begin{array}{r}1 \\
(0,8)\end{array}$ & $\begin{array}{r}5 \\
(4,0)\end{array}$ & 0,14 \\
\hline
\end{tabular}

* Teste Qui-quadrado $(p<0,05)$.

Fonte: As autoras (2017). 
Dentre os alimentos processados/ultraprocessados investigados, destacam-se os seguintes resultados, baseados na frequência de consumo e considerando alimentos prontos para o consumo ou de fácil preparação. Nesse grupo, um dos itens investigados foi o macarrão instantâneo. A maioria dos participantes informou não consumir ou consumir raramente, contudo $11,5 \%$ dos homens mencionaram consumo de 4 a 6 x/semana. As razões para evitar o consumo de ultraprocessados estendem-se desde o consumo excessivo de sódio bem como ao excesso de calorias que, por sua vez, quando não metabolizadas pelo organismo, culminam com o acúmulo de gordura corporal, como sobrepeso ou obesidade (BRASIL, 2014).

Louzada et al. (2015), considerando o consumo médio diário de energia dos brasileiros, verificaram que $21,5 \%$ da energia era proveniente de alimentos ultraprocessados. Observaram também que as quantidades de micronutrientes encontradas nesses alimentos eram bem menores que as encontradas nos alimentos in natura, destacando-se a vitamina B12, C e magnésio, cujos teores foram, respectivamente, 4, 5 e 13 vezes menores nos alimentos ultraprocessados.

Quanto ao consumo de embutidos, a maioria dos participantes de ambos os sexos relataram não consumir ou raramente consumi-los, contudo as mulheres relataram não consumir com maior frequência do que os homens. Mesmo sendo uma categoria de alimentos de fácil preparo, custo reduzido e sabor realçado, percebemos não fazer parte do hábito dos idosos deste estudo, sendo consumidos esporadicamente.

Em relação aos doces industrializados, os homens apresentaram maior consumo diário (15,4\%) quando comparado com as mulheres (7,1\%). O fato de que os homens apresentam um padrão de vida marcado pela maior carga de trabalho, com maior consumo de alimentos fora de casa, pela dificuldade de procurar por cuidado de saúde, pode ser uma justificativa às diferenças que são observadas na qualidade do consumo de alimentos e nos fatores associados à qualidade da dieta entre homens e mulheres (ASSUMPÇÃO et al., 2017).

Por outro lado, de acordo com os resultados da Vigitel obtidos em 2016, a frequência de consumo de alimentos doces em cinco ou mais dias da semana foi maior entre mulheres $(19,7 \%)$ do que entre homens $(16,0 \%)$. 
No entanto esse comportamento foi mais frequente entre os mais jovens (BRASIL, 2017), possivelmente pelo fato de os idosos ainda possuírem uma memória alimentar mais tradicional, e o consumo de doces manter-se mais frequente em dias ou datas comemorativas.

Sobre as bebidas açucaradas, as mulheres relataram com maior frequência não consumir refrigerantes e sucos industrializados. Considerando dados da pesquisa Vigitel, no ano de 2018, a frequência do consumo de refrigerantes em cinco ou mais dias da semana para indivíduos com 65 anos e mais mostrou-se maior entre homens $(10,8 \%)$ do que entre mulheres (6,3\%) (BRASIL, 2019).

Além de analisar a frequência de consumo de alimentos in natura, processados e ultraprocessados, um dos objetivos propostos foi investigar o conhecimento sobre a existência do Guia Alimentar para a População Brasileira, compreendido como um instrumento de orientação nutricional e promoção da saúde para os diversos estágios de vida, o qual deveria integrar atendimentos básicos na área da saúde, por meio de consultas com profissionais nutricionistas ou mesmo atividades educativas em grupos multidisciplinares, nos quais as orientações nutricionais podem representar condutas de tratamento decisivas para a prevenção/controle de patologias associadas à alimentação.

O objetivo principal do Guia Alimentar, publicado inicialmente em 2008, é contribuir para melhorar os padrões de alimentação e nutrição da população e facilitar o acesso a conhecimentos sobre características e determinantes de uma alimentação adequada e saudável para ampliar a autonomia e nortear as escolhas alimentares (BRASIL, 2008). Contudo, para que esse objetivo seja alcançado e os propósitos consolidados, são necessárias estratégias de saúde pública para que o documento alcance a população.

Na presente pesquisa, ao serem questionados sobre o conhecimento desse documento, 74,3\% dos participantes relataram não conhecer e/ou nunca terem ouvido falar a respeito.

Sobre a associação entre o recebimento de orientações por profissionais de saúde e comportamentos saudáveis, Flores et al. (2018) mencionam a importância do aconselhamento sobre hábitos saudáveis e sobre o estilo de vida para idosos. Além disso, a capacitação de profissionais, de todos os 
níveis de cuidados à saúde, é essencial para a efetividade de ações voltadas à promoção de hábitos saudáveis e prevenção de doenças.

$\mathrm{Na}$ Tabela 4, são apresentados os resultados a respeito do diagnóstico de DCNTs e a frequência de casos. Constatou-se que, dentre as doenças relatadas, a osteoporose esteve significativamente associada ao sexo feminino $(p=0,01)$.

Tabela 4 - Frequência de Doenças Crônicas Não Transmissíveis (DCNTs) em uma amostra de idosos ( $n=152)$, de acordo com o sexo, de Campo Grande, MS, 2017

\begin{tabular}{|c|c|c|c|c|c|}
\hline \multirow{2}{*}{$\begin{array}{l}\text { Doenças Crônicas Não } \\
\text { Transmissíveis (DCNTs) }\end{array}$} & \multicolumn{2}{|c|}{$\begin{array}{c}\text { Masculino } \\
\mathrm{n}=\mathbf{2 6}\end{array}$} & \multicolumn{2}{|c|}{$\begin{array}{c}\text { Feminino } \\
n=126\end{array}$} & \multirow{2}{*}{$\mathbf{p}$} \\
\hline & $\mathrm{n}$ & $\%$ & $\mathrm{n}$ & $\%$ & \\
\hline \multicolumn{6}{|l|}{ Presença de DCNTs } \\
\hline 1 a 2 & 16 & 61,5 & 61 & 48,4 & \\
\hline 3 ou mais & 1 & $3,8^{b}$ & 39 & $31,0^{\mathrm{a}}$ & $0,01^{*}$ \\
\hline Não tem & 9 & 34,7 & 26 & 20,6 & \\
\hline \multicolumn{6}{|l|}{ DCNTs relatadas } \\
\hline Artrite & 0 & 0,0 & 19 & 15,1 & \\
\hline Artrose & 1 & 3,8 & 26 & 20,6 & \\
\hline Câncer & 1 & 3,8 & 3 & 2,4 & \\
\hline Diabetes mellitus tipo 2 & 6 & 23,1 & 28 & 22,2 & \\
\hline Doença Respiratória & 1 & 3,8 & 8 & 6,3 & $0,01^{*}$ \\
\hline Hipertensão arterial & 15 & 57,7 & 79 & 62,7 & \\
\hline Osteoporose & 0 & $0,0^{b}$ & 27 & $21,4^{a}$ & \\
\hline Reumatismo & 0 & 0,0 & 6 & 4,8 & \\
\hline Outras & 0 & 0,0 & 21 & 16,7 & \\
\hline
\end{tabular}

Nota: As letras nas linhas indicam as diferenças estatisticamente calculadas; * Teste Quiquadrado $(p<0,05)$.

Fonte: As autoras (2017).

Sabe-se que, entre idosos, existe o risco de mais de uma doença manifestar-se concomitantemente. Nesta amostra, nota-se percentual expressivo de homens e mulheres com duas morbidades simultaneamente. Ainda, foi significativamente maior a frequência de três ou mais DCNTs entre as idosas $(p=0,01)$. É importante destacar que o fato de as mulheres 
procurarem mais os serviços de saúde pode interferir nesse resultado, por apresentarem mais diagnósticos quando comparadas aos homens.

Sobre a presença de DCNTs, Silveira, Vieira e Souza (2018), em uma amostra composta por 418 idosos, encontraram a ocorrência de 2 a 3 morbidades em 62,94\% das mulheres e em 36,62\% dos homens. Segundo as autoras, a associação de morbidades, notadamente quando constituem fatores de risco para o desenvolvimento de doenças cardiovasculares, incita preocupações sobre a abordagem de medidas preventivas de saúde.

Quanto à osteoporose, nesta amostra observada apenas entre as mulheres, segundo Camargos e Bomfim (2017), além da prevalência aumentar como avanço da idade, observa-se que a população feminina possui maiores prevalências que a masculina. De acordo com os autores, aos 80 anos, 38\% das mulheres apresentavam osteoporose, enquanto que entre os homens, a proporção foi de 10\%. Tais resultados destacam a importância da inserção de alimentos fontes de cálcio na dieta, pois favorecem a regulação do metabolismo ósseo, sendo benéfica a sua utilização regular, levando-se em conta as alterações fisiológicas que acometem esse estágio da vida (FERREIRA et al., 2017).

Constatou-se, em ambos os sexos, que a Hipertensão arterial e o Diabetes mellitus tipo 2 foram as doenças mais frequentes.

Os resultados do presente trabalho aproximam-se aos referentes ao ano de 2018, de representatividade nacional, os quais apontam frequência de Hipertensão de 56,7\% entre os homens e 63,6\% entre as mulheres com 65 anos ou mais de idade. Para o Diabetes, nesta mesma faixa de idade, $24,6 \%$ dos homens e 22,2\% das mulheres afirmaram tal diagnóstico (BRASIL, 2019). Conforme os indivíduos envelhecem, as DCNTs transformam-se nas principais causas de morbidade, incapacidade e mortalidade em idosos (MORAES, 2012). Com isso, é evidente que a autonomia e as atividades cotidianas dos indivíduos com hipertensão e diabetes podem ser afetadas durante o processo de envelhecimento, principalmente nos domínios psicológico e ambiental, e na autonomia das atividades presentes, passadas e futuras, refletindo em impactos negativos (SOUZA et al., 2016). 


\section{CONCLUSÃO}

As mulheres desta pesquisa apresentaram menor frequência de consumo de alimentos ultraprocessados e maior para alimentos in natura (frutas, verduras e legumes), quando comparada com os homens. O hábito de não fumar e frequência semanal de atividade física $\geq 3$ dias associaram-se ao sexo feminino, contudo a frequência de três ou mais DCNTs também foi significativamente maior entre as idosas. Dentre as DCNTs, a Hipertensão Arterial e Diabetes apresentaram maior frequência de diagnóstico.

\section{REFERÊNCIAS}

ANDRADE, A. N.; NASCIMENTO, M. M. P.; OLIVEIRA, M. M. D.; QUEIROGA, R. M.; FONSECA, F. L. A.; LACERDA, S. N. B.; ADAMI, F. Percepção de idosos sobre grupo de convivência: estudo na cidade de Cajazeiras-PB. Revista Brasileira de Geriatria e Gerontologia, Rio de Janeiro, v. 17, n. 1, p. 39-48, jan./mar. 2014. Disponível em: http://www.scielo.br/scielo.php?script=sci_arttext\&pid=S180998232014000100039\&lng=pt\&nrm=iso\&tlng=pt. Acesso em: 5 mar. 2019.

ASSUMPÇÃO, D.; DOMENE, S. M. A.; FISBERG, R. M.; CANESQUI, A. M.; BARROS, M. B. A. Diferenças entre homens e mulheres na qualidade da dieta: estudo de base populacional em Campinas, São Paulo. Ciência \& Saúde Coletiva, Rio de Janeiro, v. 22, n. 2, p. 347-58, fev. 2017. Disponível em: http://www.scielo.br/pdf/csc/ v22n2/1413-8123-csc-22-02-0347.pdf. Acesso em: 14 nov. 2017.

BARBOSA, M. B.; PEREIRA, C. V.; CRUZ, D. T.; LEITE, I. C. G. Prevalência e fatores associados ao consumo de álcool e de tabaco em idosos não institucionalizados. Revista Brasileira de Geriatria e Gerontologia, Rio de Janeiro, v. 21, n. 2, p. 12535, abr./mar. 2018. Disponível em: http://www.scielo.br/scielo.php?script=sci_ arttext\&pid=S1809-98232018000200123\&Ing=pt\&nrm=iso\&tlng=pt. Acesso em: 5 mar. 2019.

BENEDETTI, T. R. B.; MAZO, G. Z.; BORGES, L. J. Condições de saúde e nível de atividade física em idosos participantes e não participantes de grupos de convivência de Florianópolis. Ciência \& Saúde Coletiva, Rio de Janeiro, v. 17, n. 8, p. 2087-93, ago. 2012. Disponível em: http://www.scielo.br/pdf/csc/v17n8/19. pdf. Acesso em: 17 jun. 2018.

BOTTON, A.; CÚNICO, S. D.; STREY, M. N. Diferenças de gênero no acesso aos serviços de saúde: problematizações necessárias. Mudanças - Psicologia da 
Saúde, São Bernardo do Campo, SP, v. 25, n. 1, p. 67-72, jan./jun. 2017. Disponível em: http://www.metodista.br/revistas/revistas-ims/index.php/MUD/article/ view/7009/5608. Acesso em: 14 nov. 2017.

BRASIL . Ministério da Saúde. Secretaria de Vigilância em Saúde. Departamento de Análise em Saúde e Vigilância de Doenças não Transmissíveis. Vigitel Brasil 2018: vigilância de fatores de risco e proteção para doenças crônicas por inquérito telefônico: estimativas sobre frequência e distribuição sociodemográfica de fatores de risco e proteção para doenças crônicas nas capitais dos 26 estados brasileiros e no Distrito Federal em 2018. Brasília: Ministério da Saúde, 2019.132p. Disponível em: http://portalarquivos2.saude.gov.br/images/pdf/2019/julho/25/vigitelbrasil-2018.pdf. Acesso em: 29 jul. 2019.

BRASIL. Ministério da Saúde. Secretaria de Vigilância em Saúde. Departamento de Vigilância de Doenças e Agravos não Transmissíveis e Promoção da Saúde. Vigitel Brasil 2017: vigilância de fatores de risco e proteção para doenças crônicas por inquérito telefônico: estimativas sobre frequência e distribuição sociodemográfica de fatores de risco e proteção para doenças crônicas nas capitais dos 26 estados brasileiros e no Distrito Federal em 2017. Brasília: Ministério da Saúde, 2018. 130 p. Disponível em: http://bvsms.saude.gov.br/bvs/publicacoes/vigitel_brasil_2017_ vigilancia_fatores_riscos.pdf. Acesso em: 30 ago. 2018.

BRASIL. Ministério da Saúde. Secretaria de Vigilância em Saúde. Departamento de Vigilância de Doenças e Agravos não Transmissíveis e Promoção da Saúde. Vigitel Brasil 2016: vigilância de fatores de risco e proteção para doenças crônicas por inquérito telefônico: estimativas sobre frequência e distribuição sociodemográfica de fatores de risco e proteção para doenças crônicas nas capitais dos 26 estados brasileiros e no Distrito Federal em 2016. Brasília: Ministério da Saúde, 2017. 160 p. Disponível em: http://portalarquivos.saude.gov.br/images/pdf/2017/junho/07/ vigitel_2016_jun17.pdf. Acesso em: 15 nov. 2017.

BRASIL. Ministério da Saúde. Secretaria de Atenção à Saúde. Departamento de Atenção Básica. Guia Alimentar para a População Brasileira. 2. ed., 1. reimpr. Brasília, DF: Ministério da Saúde, 2014. 156 p. Disponível em: http://bvsms.saude. gov.br/bvs/publicacoes/guia_alimentar_populacao_brasileira_2ed.pdf. Acesso em: 14 nov. 2017.

BRASIL. Ministério da Saúde. Secretaria de Atenção à Saúde. Departamento de atenção Básica. Alimentação saudável para a pessoa idosa: um manual para profissionais de saúde. Brasília, DF: Ministério da Saúde, 2009. 36 p. Disponível 
em: http://bvsms.saude.gov.br/bvs/publicacoes/alimentacao_saudavel_idosa_ profissionais_saude.pdf. Acesso em: 14 nov. 2017.

BRASIL. Ministério da Saúde. Secretaria de Atenção à Saúde. Departamento de Atenção Básica. Guia alimentar para a população brasileira: promovendo a alimentação saudável. 1. ed., 1. reimp. Brasília, DF: Ministério da Saúde, 2008. 210 p. Disponível em: http://bvsms.saude.gov.br/bvs/publicacoes/guia_alimentar_ populacao_brasileira_2008.pdf. Acesso em: 14 nov. 2017.

BUSATO, M. A.; GALLINA, L. S.; TEO, C. R. P. A.; FERRETI, F.; POZZAGNOL, M. Autopercepção de saúde e vulnerabilidade em idosos. Revista Baiana de Saúde Pública, [s. I.], v. 38, n. 3, p. 625-35, jul./set. 2014. Disponível em: http://rbsp.sesab. ba.gov.br/index.php/rbsp/article/view/726. Acesso em: 5 mar. 2019.

CAMARGOS, M. C. S.; BOMFIM, W. C. Osteoporose e Expectativa de Vida Saudável: estimativas para o Brasil em 2008. Cadernos de Saúde Coletiva, Rio de Janeiro, v. 25, n. 1, p. 106-12, jan./mar. 2017. Disponível em: http://www.scielo.br/pdf/ cadsc/2017nahead/1414-462X-cadsc-1414-462X201700010150.pdf. Acesso em: 14 nov. 2017.

CARVALHO, D. A.; BRITO, A. F.; SANTOS, M. A. P.; NOGUEIRA, F. R. S.; SÁ, G. G. M.; OLIVEIRA NETO, J.; MARTINS, M. C. C.; SANTOS, E. P. dos. Prevalência da prática de exercícios físicos em idosos e sua relação com as dificuldades e a falta de aconselhamento profissional específico. Revista Brasileira de Ciência e Movimento, Brasília, v. 25, n. 1, p. 29-40, 2017. Disponível em: https://portalrevistas.ucb.br/ index.php/RBCM/article/view/6467/pdf. Acesso em: 14 nov. 2017.

CENTRO DE CONVIVÊNCIA DO IDOSO. In: Secretaria Municipal de Assistência Social. Campo Grande (MS), [2019?]. Disponível em: http://www.campogrande.ms.gov. br/sas/cci/. Acesso em: 4 mar. 2019.

FERREIRA, C. T. P. A.; TEIXEIRA, C. M. S.; ARAÚJO, M. L. M.; SIQUEIRA, A. B. L. Benefícios nutricionais compostos no leite e seus derivados para a população geriátrica. Revista Brasileira de Agrotecnologia, Garanhuns, PE, v. 7, n. 1, p. 122-5, 2017. Disponível em: http://www.gvaa.com.br/revista/index.php/REBAGRO/article/ view/4699/122-125. Acesso em: 14 nov. 2017.

FLORES, T. R.; GOMES, A. P.; SOARES, A. L. G.; NUNES, B. P.; ASSUNÇÃO, M. C. F.; GONÇALVES, H.; BERTOLDI, A. D. Aconselhamento por profissionais de saúde comportamentos saudáveis entre idosos: estudo de base populacional em Pelotas, sul do Brasil, 2014. Epidemiologia e Serviços de Saúde, Brasília, v. 27, n. 1, p. 1-11, 
fev. 2018. Disponível em: http://www.scielo.br/pdf/ress/v27n1/2237-9622-ress27-01-e201720112.pdf. Acesso em: 27 jun. 2018.

LINDEMANN, I. L.; OLIVEIRA, R. R.; MENDOZA-SASSI, R. A. Dificuldades para alimentação saudável entre usuários da atenção básica em saúde e fatores associados. Revista Ciência \& Saúde Coletiva, Rio de Janeiro, v. 21, n. 2, p. 599610, fev. 2016. Disponível em: http://www.scielo.br/pdf/csc/v21n2/1413-8123csc-21-02-0599.pdf. Acesso em: 5 mar. 2019.

LOUZADA, M. L. C.; MARTINS, A. P. B.; CANELLA, D. S.; BARALDI, L. G.; LEVY, R. B.; CLARO, R. M.; MOUBARAC, J.; CANNON, G.; MONTEIRO, C. A. Impacto de alimentos ultraprocessados sobre o teor de micronutrientes da dieta no Brasil. Revista de Saúde Pública, São Paulo, v. 49, n. 45, p. 1-8, jul. 2015. Disponível em: http://www. scielo.br/pdf/rsp/v49/0034-8910-rsp-S0034-89102015049006211.pdf. Acesso em: 14 nov. 2017.

LUIS, M. A. V.; GARCIA, M. V. L.; BARBOSA, S. P.; LIMA, D. W. C. O uso de álcool entre idosos atendidos na Atenção Primária à Saúde. Acta Paulista de Enfermagem, São Paulo, v. 31, n. 1, p. 46-53, jan./fev. 2018. Disponível em: http://www.scielo.br/ scielo.php?script=sci_arttext\&pid=S0103-21002018000100046\&lng=pt\&nrm=iso \&tIng=pt. Acesso em: 25 jun. 2018.

MARTINS, A.; PARENTE, J.; ARAÚJO, J.; MENEZES, M. J. Prevalência do consumo de risco de álcool no idoso: estudo numa unidade dos cuidados primários da região de Braga. Revista Portuguesa de Medicina Geral e Familiar, Lisboa, v. 32, n. 4, p. 270-4, ago. 2016. Disponível em: http://www.scielo.mec.pt/pdf/rpmgf/v32n4/ v32n4a07.pdf. Acesso em: 14 nov. 2017.

MESSIAS, A. R. Gênero e mídia: um olhar sobre a mulher idosa em narrativas fílmicas brasileiras. Interfaces Científicas - Humanas e Sociais, Aracaju, v. 1, n. 1, p. 17-29, out. 2012. Disponível em: https://periodicos.set.edu.br/index.php/ humanas/article/view/398. Acesso em: 5 mar. 2019.

MORAES, E. N. Atenção à saúde do idoso: aspectos conceituais. Brasília: Organização Pan-Americana da Saúde, 2012. 98 p. Disponível em: http://apsredes.org/pdf/ Saude-do-Idoso-WEB1.pdf. Acesso em: 14 nov. 2017.

ORGANIZAÇÃO PAN-AMERICANA DA SAÚDE (OPAS). Atenção à saúde do idoso: aspectos conceituais. Organização do Trabalho da Representação da OPAS/OMS no Brasil. Brasília, DF: OPAS, 2012. 98 p. 
PAN AMERICAN HELTH ORGANIZATION. Department of Noncommunicable Diseases and Mental Health Regional. Regional Status Report on Alcohol and Health in theAmericas. Washington, DC: PAHO, 2015. 80 p. Disponível em: http://www.paho. $\mathrm{org} / \mathrm{hq} /$ index.php?option=com_content $\&$ view $=$ article \&id $=11108 \&$ temid $=41530$ \&lang=en. Acesso em: 7 set. 2018.

SALES, J. C. S.; SILVA JÚNIOR, F. J. G.; VIEIRA, C. P. B.; FIGUEIREDO, M. L. F.; LUZ, M. H. B. A.; MONTEIRO, C. F. S. Feminização da velhice e sua interface com a depressão: revisão integrativa. Revista de Enfermagem UFPE Online, Recife, v. 10, n. 5, p. 1840-6, maio 2016. Disponível em: https://periodicos.ufpe.br/revistas/ revistaenfermagem/article/view/13564. Acesso em: 5 mar. 2019.

SALGADO, C. D. S. Mulher idosa: a feminização da velhice. Estudos Interdisciplinares sobre o Envelhecimento, Porto Alegre, v. 4, p. 7-19, 2002. Disponível em: https:// seer.ufrgs.br/RevEnvelhecer/article/view/4716. Acesso em: 5 mar. 2019.

SANTANA, J. O.; RAMALHO, J. R. O.; FIRMO, J. O. A.; LIMA-COSTA, M. F.; PEIXOTO, S. $\checkmark$. Atividade física e escore de risco de Framingham entre idosos: Projeto Bambuí. Cadernos de Saúde Pública, Rio de Janeiro, v. 31, n. 10, p. 2235-40, out. 2015. Disponível em: https://www.arca.fiocruz.br/bitstream/icict/14839/2/ve_Santana_ Jaqueline_\%20Atividade_CPqRR_2015.pdf. Acesso em: 14 nov. 2017.

SILVA, E. F.; LASTE, G.; TORRES, R. L.; HIGALGO, M. P. L.; STROHER, R.; TORRES, I. L. S. Consumo de álcool e tabaco: fator de risco para doença cardiovascular em população idosa do sul do Brasil. Revista Saúde e Desenvolvimento Humano, Canoas, RS, v. 5, n. 1, p. 23-33, fev. 2017. Disponível em: https://www.researchgate. net/profile/II_Torres/publication/314191502_Consumo_de_alcool_e_tabaco_ fator_de_risco_para_doenca_cardiovascular_em_populacao_idosa_do_sul_ do_Brasil/links/593ebc38458515a6215a02e6/Consumo-de-alcool-e-tabacofator-de-risco-para-doenca-cardiovascular-em-populacao-idosa-do-sul-do-Brasil. pdf?origin=publication_detail. Acesso em: 6 set. 2018.

SILVA, S. P. C.; MENANDRO, M. C. S. As representações sociais da saúde e de seus cuidados para homens e mulheres idosos. Saúde e Sociedade, São Paulo, v. 23, n. 2, p. 626-40, abr./jun. 2014. Disponível em: http://www.scielo.br/scielo. php?script=sci_arttext\&pid=S0104-12902014000200626\&lng=pt\&tlng=pt. Acesso em: 14 nov. 2017.

SILVA, H. O.; CARVALHO, M. J. A. D.; LIMA, F. E. L.; RODRIGUES, L. V. Perfil epidemiológico de idosos frequentadores de grupos de convivência no município de Iguatu, Ceará. Revista Brasileira de Geriatria e Gerontologia, Rio de Janeiro, v. 
14, n. 1, p. 123-33, jan./mar. 2011. Disponível em: http://www.scielo.br/scielo. php?script=sci_arttext\&pid=S1809-98232011000100013. Acesso em: 5 mar. 2019.

SILVEIRA, E. A.; VIEIRA, L. L.; SOUZA, J. D. Elevada prevalência de obesidade abdominal em idosos e associação com diabetes, hipertensão e doenças respiratórias. Ciência \& Saúde Coletiva, Rio de Janeiro, v. 23, n. 3, p. 903-12, mar. 2018. Disponível em: http://www.scielo.br/scielo.php?script=sci_arttext\&pid=S1413$81232018000300903 \&$ Ing=en\&nrm=iso\&tlng=pt. Acesso em: 27 jun. 2018.

SOUZA, J. D.; MARTINS, M. V.; FRANCO, F. S.; MARTINHO, K. O.; TINÔCO, A. L. Padrão alimentar de idosos: caracterização e associação com aspectos socioeconômicos. Revista Brasileira de Geriatria e Gerontologia, Rio de Janeiro, v. 19, n. 6, p. 970-7, nov./dez. 2016. Disponível em: http://www.scielo.br/pdf/rbgg/v19n6/pt_18099823-rbgg-19-06-00970.pdf. Acesso em: 14 nov. 2017.

TABELA DE COMPOSIÇÃO QUÍMICA DOS ALIMENTOS. Departamento de Informática em Saúde. Escola Paulista de Medicina. Universidade Federal de São Paulo, São Paulo, 2016. Disponível em: http://tabnut.dis.epm.br/. Acesso em: 14 nov. 2017.

WORLD HEALTH ORGANIZATION. Preventing chronic diseases: a vital investment: WHO global report. Geneva: Word Health Organization, 2005. 34 p. Disponível em: http://apps.who.int/iris/bitstream/10665/43314/1/9241563001_eng.pdf. Acesso em: 14 nov. 2017.

WORLD HEALTH ORGANIZATION. Diet, nutrition and the prevention of chronic diseases: report of a joint WHO/FAO expert consultation. Geneva: Word Health Organization, 2003. 160 p. Disponível em: http://apps.who.int/iris/ bitstream/10665/42665/1/WHO_TRS_916.pdf. Acesso em: 20 nov. 2017. 